\title{
El delito de brujería en el Libro Segundo de las Disquisitionum Magicarum de Martín del Río
}

\author{
Raúl Madrid \\ FACULTAD DE DERECHO. \\ PONTIFICIA UNIVERSIDAD CATÓLICA DE CHILE \\ rmadrid@uc.cl
}

Resumen: El presente trabajo tiene por objeto analizar, en contraste con las obras anteriores y contemporáneas sobre el tema, el concepto, característica, acciones típicas y límites del llamado delito de brujería en el libro II de la obra Disquisitionum Magicarum, del inquisidor español Martín del Río; obra de gran influencia en todo el Santo Oficio desde 1610. Para esto, se describen tres conductas típicas: el pacto con el demonio, el maleficio, y el vuelo nocturno hacia el aquelarre o sabbat. Además de analizar la novedad del aporte de Del Río, el trabajo se ocupa de la relevancia teológica de su obra, que presenta los actos de la bruja en estrecha vinculación con las fuerzas del demonio.

Palabras clave: Brujería. Pacto con el demonio. Maleficio. Aquelarre.

Abstract: This paper aims to analyze the concept, traits, typical actions and limits of the crime of witchcraft in book II of Martín del Rio's Disquisitionum Magicarum, by comparing it with previous and contemporary doctrine. Del Rio's work was of great influence since 1610. To fullful this task, three typical behaviors are described: the pact with the devil, the hex and the attending to aquelarre or sabbat. Along with considering novelty in the del Río's work, the paper deals with the theological significance of the book, which describes the acts of witchcraft as closely associated to demonic forces.

Key words: Witchcraft. Pact with the Devil. Hex. Sabbat. 


\section{MARTÍN DEL RÍO Y LAS DISQUISITIONUM MAGICARUM}

Martín Antonio del Río y López de Villanueva nació en Amberes en 1551, hijo de un noble castellano y de una acomodada familia aragonesa. Se dice que por el linaje de su madre se emparentaba con Antonieta López, la madre de Montaigne, todos ellos provenientes de la judería de Calatayud. El joven Martín tuvo a su disposición los medios para adquirir una excelente educación ${ }^{1}$, y realizó estudios superiores en París, Douay, Graz, Lovaina (donde obtuvo el material para sus investigaciones demonológicas), Salamanca y Bruselas. En París fue discípulo de Juan Maldonado, que conocía entre otros asuntos de estudios cabalísticos y demonológicos y había publicado un tratado titulado De doemonibus en $1570^{2}$. De hecho, en el prólogo de las Disquisiciones, Del Río resume un seminario de Maldonado sobre demonología.

En Lovaina estudió Derecho, con especial vocación filológica, graduándose de bachiller en Derecho Civil en 1570. Luego, en Salamanca, se convirtió en Utriusque Iuris licenciatus: licenciado en ambos derechos: civil y canónico. En 1575 Felipe II le otorgó el nombramiento de consejero para la Cancillería del Brabante, con sede en Bruselas. De regreso en los Países Bajos, emprendió una corta carrera civil, que coincide con los años de gobierno de su protector, don Juan de Austria. Durante estos

1 Se dice que conocía bien a los clásicos, y que dominaba el hebreo, el caldeo y cinco lenguas modernas; además de ser versado en leyes. A los diecinueve años publicó una versión de Séneca, con más de mil trescientas citas de su autoría. Cf. R. Hope RobBins, Enciclopedia de la brujería y demonología (Debate, Barcelona, 1988) 211.

2 Juan Maldonado (1534-1583). Jesuita español reconocido como el mayor exégeta del siglo XVI, y un agudo teólogo de la Contrarreforma. Nació en Casas de la Reina (Extremadura) en 1534. Fue profesor de teología y filosofía en París en donde gozó de un gran prestigio. Su trabajo contra los calvinistas lo lleva a producir un texto liminar, la Oratio de disputatione de 1574. Maldonado renueva profundamente, además, la enseñanza de la teología positiva en favor de un retorno a las fuentes de la escritura y los Padres de la Iglesia. Traba conocimiento y amistad con Juan de Mariana y con el mismo Montaigne. En 1581 es convocado por el Papa Gregorio XIII para que revise el texto griego de la nueva edición de la Biblia conocida como las Setenta. Muere súbitamente en Roma en 1583. El texto De Doemonibus fue traducido al francés en 1605 con el título de Traicté des anges et demons, y lo convirtió en una de las grandes figuras de la demonología de la época. Allí sostiene que "los demonios ejercen su poder no solo sobre la voluntad del hombre sino también sobre los cuerpos humanos y sobre las cosas exteriores". Cf. E. Asensio y J. AlCinA Rovira, Juan Paraenesis ad Litteras. Juan Maldonado y el Humanismo español en tiempos de Carlos V(Fundación Universitaria, Madrid, 1980). 
años despliega su proverbial capacidad de trabajo, que le llevaba a estar de la mañana a la noche en su biblioteca. Se afirmaba que había leído todos los fondos bibliográficos belgas; pero no de corrido, sino despacio y tomando notas ${ }^{3}$. Este período termina en 1580, cuando solicita formalmente su ingreso en la Compañía de Jesús. Es admitido sin obstáculos en Valladolid, el 9 de mayo de 1580, a la edad de 29 años. A partir de 1589, de regreso en Lovaina, se dedica por completo a la docencia e investigación. Por alguna razón, se le encarga ese mismo año un curso de Demonología, y otro de filosofía natural. Esta época se forjan las bases de las Disquisiciones, componiendo la enciclopedia sobre superstición y malas artes. Después de doctorarse en Teología en Graz, pasó a Salamanca en 1603, donde continuó su trabajo intelectual. Murió en Lovaina, en 1608, a los 58 años de edad.

Las Disquisiciones mágicas constituye su obra enciclopédica y capital ${ }^{4}$, y la más famosa de su extensa producción ${ }^{5}$. Este trabajo es una de las obras más completas sobre brujería, y tan conocida como el Malleus Maleficarum $^{6}$.

3 Se cuenta que, después de tomar un mendrugo de pan con vino dulce por la mañana, se encerraba en la biblioteca y, utilizando una invención propia, consistente en una especie de asiento-pupitre con ruedas movido a pedales, se trasladaba por toda la estancia, evitando tener que ponerse de pie, cada vez, para tomar un volumen de las estanterías. H. Huster, S.J., Nomenclator, 3, 489-94.

4 Disquisitionum magicarum libri sex in tres tomos partiti, auctore Martino delrio, Societatis Iesu Presbytero. Lovaina, Gerardo Rivio, 1599, con dedicatoria al Príncipe Obispo de Lieja. Antes de la edición completa, apareció anticipadamente el primer tomo, con objeto de estar presente en la feria del libro de Frankfurt. Como puede constatarse a propósito de la siguiente anécdota, la historia muestra que la condición humana es siempre la misma: Del Río se queja en un escrito de haber visto en un catálogo de la misma feria, pero del mes de noviembre, el anuncio de una edición pirata del referido primer tomo, donde, para mayores señas, se suprimía su condición de jesuita. La obra fue reeditada varias veces, y en 1611 fue traducida al francés. En 1747 -fecha de la última edición- existían ya aproximadamamente veinte.

5 Durante los veintisésis años dedicados al estudio y a la investigación, escribió, además, al menos quince libros de sermones y comentarios. Su obra refleja un caudal de erudición verdaderamente impresionante sobre cuestiones de astrología, astronomía, alquimia, biología y meteorología y, a la vez, una exposición compacta, de inestimable valor folclórico. Cf. J. L. Laurenti, "Martín del Río, S. J. (15511608), obras localizadas”, en Anales de Literatura Española 5 (1986-1987) 231.

6 R. Hope Robbins, Enciclopedia..., voz Del Río, Martín, 211. 
Cabe apuntar que no es muy alto el número de obras dedicadas a estas cuestiones en España, al menos con anterioridad a los siglos XVI y XVII ${ }^{7}$. Es a comienzos del siglo XVI, cuando aumentan en Europa los procesos por brujería, que el género cobra importancia más allá de los Pirineos, con gran influencia francesa. La obra de Del Río tiene seis libros, apareciendo la primera "entrega" (libros I y II) durante el otoño de 1599, en Lovaina. Para hacerse una idea del valor y significado del capítulo objeto de este trabajo, conviene mencionar el contenido completo de la obra. Su estructura general es la siguiente (que no coincide con la separación en seis libros): (1) una parte introductoria, donde se discute qué es la magia y sus diversos tipos: natural, artificial (alquimia) y demoníaca. La segunda parte (2) -objeto de nuestra atención- versa directamente sobre esta última forma de magia, a lo largo de treinta cuestiones. Se trata de la magia diabólica; las brujas en el aquelarre; íncubos; apariciones reales y falsas, etc. El mismo Del Río consideraba esta sección como la fundamental de la obra. La tercera parte (3) se refiere a la superstición, los maleficios y las observancias vanas; cómo se llevan a cabo los maleficia; cómo y por qué permite Dios que los hombres sean atormentados por espíritus malignos. La cuarta parte (4) versa sobre las profecías, la adivinación -tanto cuando se trata de herejías como de simples supersticiones-; sobre el llamado "juicio de Dios", bain des sorciers o "prueba del agua”. La quinta parte (5) aborda las recomendaciones a los jueces: los indicios y las pruebas de la brujería deben ser considerados como pruebas de herejía, aun cuando Del Río sugiere la prudencial benevolencia de los jueces. Por último, la sexta parte (6) apunta a las

Además de la obra que nos ocupa en este trabajo, deben contarse las siguientes: Andosilla, Martín, De supertitionibus, Lyon, 1510; Casteñega, Martín de, Tratado muy sutil y bien fundado de las supersticiones y hechicerias y vanos conjuros y abusiones y otras cosas al caso tocantes y de la possibilidad y remedio dellas, Logroño, 1529 (cabe destacar que este fue el primer tratado sobre brujería impreso en lengua vernácula); Castro, Alonso de, De sortilegiis et maleficiis et eorumque punitione, Lyon, 1558; Ciruelo, Pedro, Reprovación de las supersticiones y hechicerías, Salamanca, 1538; Perer, Benito, Adversus fallaces et superstitiosas artes, id est, de magia, de observacione somniorum et de divinatione astrologica, Ingoldstadt, 1591; Lanuza, Blasco de, Combate de demonios y patrocinio de ángeles, San Juan de la Peña, 1652; Navarro, Gaspar, Tribunal de superstición ladina, Huesca, 1632; De Ribera y Andrada, Rodrigo Antonio de, Magia natural y artificial, 1632; Torreblanca Villalpando, Francisco, Epitomes delictorum in quibus aperta, vel oculta invocatio daemonis intervenit, Sevilla, 1618. 
funciones del confesor, y a los medios naturales (como el coral) y sobrenaturales (como el exorcismo) para luchar contra los maleficia.

\section{EL CONCEPTO DE “BRUJA” EN EL LIBRO II DE LAS DISQUISITIONUM MAGICORUM}

Corresponde a continuación analizar los elementos que configuran el concepto de "bruja" y el delito de "brujería" en el libro II de las Disquisiciones. Antes que nada, parece conveniente destacar que resulta muy difícil entender la mentalidad de otra época aplicando simplemente los parámetros de nuestro tiempo, y no extrapolar categorías modernas o contemporáneas a la explicación de fenómenos que responden a paradigmas cuyas líneas directrices son epocal y culturalmente muy distintas. Por ello, la obra de Del Río y en general de los inquisidores, debe situarse en su contexto histórico-cultural para ser comprendida a cabalidad, y no deformada a través del juicio con criterios contemporáneos ${ }^{8}$.

El capítulo que nos ocupa se titula Magicarum disquisitionum tomus secundus, in quo agitur de maleficio, vanas observatione, divinatione et coiectatione, que indica con bastante precisión su contenido, a saber, lo que en Derecho Penal se conoce como "conductas típicas"; en este caso, de la bruja. Para efectos del concepto de "bruja", tomaremos por modelo la definición de West, que contiene todos los elementos que configuraron la tipicidad de la conducta: "la bruja es la mujer que, engañada por un pacto firmado con el Diablo y persuadida por este, cree que puede obrar cualesquiera actos de maldad, con el pensamiento o mediante la imprecación (maleficio)... ser transportada por su demonio familiar hasta una montaña lejana en un lapso de tiempo prodigiosamente breve, y a veces volar en un cayado otro instrumento (vuelo nocturno)... y pasar toda la noche dedicándose a otras actividades igualmente diabólicas y lujuriosas... (asamblea nocturna, aquelarre o sabbat)" .

Como sostiene Caro Baroja, tres criterios cruzaban transversalmente la opinión de Del Río sobre la brujería: (1) primero, la convicción de que la magia, en sus distintas acepciones y operaciones, es una realidad comprobada, en pie de igualdad con la ciencia y la técnica; (2) segundo,

8 F. A. Campagne, "Witchcraft and the Sense-of-the-Impossible in Early Modern Spain: Some Reflections Based on the Literature of Superstition (ca.1500-1800)", en The Harvard Theological Review 96/1 (2003) 29 (25-62).

9 W. West, Simboleography (Londres, 1594). Las referencias entre paréntesis son nuestras. 
la convicción entre católicos y protestantes de que proliferaba un mal histórico: la magia demoníaca, el satanismo y la brujería, con estereotipos como el aquelarre, y (3) la convicción generalizada entre católicos conservadores de que tal magia satánica era un epifenómeno histórico de la herejía en general, y de la Reforma en particular, y así, su represión debía inscribirse en el contexto de la Contrarreforma, cuyos paladines indiscutibles eran los jesuitas ${ }^{10}$. Esta asimilación entre herejía y brujería sería, según la doctrina, el elemento central que desata la persecución ${ }^{11}$.

Del Río menciona todas las conductas típicas: el maleficio, el vuelo nocturno y el aquelarre. Nos referiremos a ellas por separado, comenzando por la circunstancia previa del pacto con el demonio; que es para Del Río -y para todos los defensores de la existencia de la brujeríacondición de posibilidad de todas las anteriores. Dice nuestro autor: "la brujería es un arte gracias al cual, y mediante el poder de un contrato firmado con el diablo, se realizan prodigios que no puede comprender el hombre medio" ${ }^{12}$.

\subsection{El pacto con el demonio y el origen de la magia}

Comienza refutando, al principio de la cuestión 2, a los que sostienen que, aun existiendo demonios, la magia proviene inmediatamente de Dios (que obraría a través de los magos), o mediadamente a través de los ángeles ${ }^{13}$. Lo primero es imposible, argumenta, porque supedita los dones gratuitos al artificio humano, mientras que lo segundo resulta también imposible, porque Dios no se inmiscuye en las acciones mágicas más que en lo que concurre a todo, como causa universal. No vale, pues, la distinción entre teúrgia y goecia (Theourgia y Goetéia), o magia blanca y negra, respectivamente. La primera significa, literalmente, obra de Dios, y puede indicar también el milagro. La segunda se traduce como quejumbre, de la misma raíz que goáo, suspirar ${ }^{14}$. Tampoco pue-

10 J. CARO BAROJA, Estudio introductorio a La magia demoniaca (Ediciones Hiperión, Madrid, 1990) 47.

11 Cf. G. L. Burr (ed.), Narratives of the Witchcraft Cases, 1648-1706 (Dover Publications, New York, 2002 (reimpresión del original de 1914)) 5 y ss.

12 Cit. por R. Hope Robbins, Enciclopedia ... 105.

13 J. Caro Baroja, Estudio introductorio... 173.

14 La teúrgia se establece en torno a la vida y a la magia creadora, mientras que la goecia lo hace en torno a la muerte, a la recreación y a la nigromancia. Se trata de conceptos herméticos, que tendrán gran influencia posteriormente, en la obra de 
den provenir de las almas de los difuntos -afirma, siguiendo a Vitoria ${ }^{15}$-, porque las condenadas están en el infierno por mandato divino, y las purgantes solo salen para pedir sufragio a los vivos. "Por esto juzgo -continúa- que todas esas magias las realizan los mismos ángeles malos que las instituyeron" 16 .

Así pues, para Del Río toda la magia prodigiosa es magia negra, y está corrompida porque se basa en la alianza con los demonios, a través de un pacto expreso o tácito; pacto del que deriva el carácter herético de la brujería ${ }^{17}$. Es, sin embargo, en la cuestión cuarta del libro II donde se expone esta doctrina: "todas las operaciones mágicas tienen como base algún pacto de los magos con el demonio, de suerte que cada vez que al mago le apetezca hacer algo con ayuda de su arte, tiene que pedir expresa o implícitamente al demonio que le asista según el trato" ${ }^{18}$. Y esto se demostraría primero (1) por las Escrituras, por cuanto el profeta Isaías hace decir a los impíos "hemos hecho trato con la muerte, y con el infierno hemos pactado"19, y por el pacto que el mismo Satanás ofrece a Cristo, al decirle "todo esto te daré, si postrándote me adoras"20, y (2) por la autoridad de los Padres, como las palabras de San Agustín recogidas en el Decreto de Graciano: "todas las artes de esta laya o son de broma, o de dañosa superstición, consistentes en alguna asociación

Marsilio Ficino. Cf. E. Garín, Medioevo y Renacimiento. Estudios e investigaciones (Taurus, Madrid, 1983) 211.

15 F. De Vitoria, De magia, 17.

16 M. Del Río, Disquisitionum, II, p. 175.

17 M. Del Río, Disquisitionum, q. 3. Para todos los teólogos, católicos y protestantes, este pacto constituía el elemento esencial por el que el delito de brujería era sometido a la Inquisición. Cf por ejemplo la opinión de Perkins, el primer gran teólogo anglicano: aunque la bruja fuese beneficiosa en muchos sentidos y en lugar de perjudicar obrara el bien, por haber renegado de Dios... la muerte es el justo castigo que Dios le asigna. W. Perkins, A Discourse of the Damn Art of Witchcraft. So farre forth as it is Revealed in the Scriptures and Manifested by True Experience (James Boler, Londres, 1631) 609 y ss.

18 M. Del Río, Disquisitionum, libro II, q.4. Algo similar se dice en una sentencia de 1583: "se llaman brujos o brujas a los hombres o mujeres que después de haber renegado de Dios y de la religión, se han entregado al Diablo en virtud de un pacto formal, a fin de obtener de él el poder de obrar toda clase de maravillas que serían imposibles en un orden natural”. Cf. J. BaISSAC, Le diable (M. Deyfous, París) 236.

19 ISAÍAS, 28, 15.

20 Mateo, 4, 9. 
pestífera de hombres y demonios, a manera de pactos de amistad dolosa e infiel" 21 .

Del Río utiliza también el argumento del consenso universal: "en esto -afirma- coinciden los teólogos antiguos y modernos, como también los jurisconsultos y los médicos. Y es cosa averiguada por confesión unánime de maléficos y brujas en admirable consenso por toda Europa y en todos los tiempos". Entre los antiguos debe considerarse a San Agustín ${ }^{22}$, Santo Tomás ${ }^{23}$, San Cipriano ${ }^{24}$ y Pedro de Luna ${ }^{25}$; entre los "modernos" cabe incluir a Vitoria (ya citado), Alonso de Madrigal26 y Peter Binsfeld $^{27}$. La referencia a los juristas alude especialmente al Doctor Navarro, Martín de Azpilicueta ${ }^{28}$.

Advierte Del Río que el pacto deja al demonio en libertad de cumplir o burlar, lo que se probaría tanto por la experiencia como por la razón, ya que el hombre no tiene poder sobre los ángeles ${ }^{29}$. Según nuestro autor, el delito de brujería se consumaría pues a través del pacto, que, en su modalidad expresa tiene tres formas o conductas típicas ${ }^{30}:$ (1) la

21 San Agustín, La doctrina cristiana, 1, 2, 23, 36. El texto, como se indica, fue recogido en el Decreto de Graciano, 26, 2.

22 SAn Agustín, La doctrina cristiana, q. 23: "las supercherías de los magos tienen su origen en el pestífero comercio del hombre con el demonio".

23 Santo Tomás, Summa Theologiae, I, q. 110 a 114 y II-II, q.90: "Los demonios son nuestros enemigos en el curso de esta vida presente. Sus actos, sin embargo, no se someten a nuestras disposiciones, sino a las órdenes de Dios y a las de los santos ángeles, pues, como dice San Agustín, el espíritu malo es regido por el espíritu justo... no es lícito, en cambio, conjurarlos para aprender y obtener alguna cosa por su medio, ya que con esto estableceríamos relaciones con ellos".

24 De duplicü martirio, q. 2: "el prestigio de los magos procede de la alianza con Satanás".

25 P. De LunA, Libro de las consolaciones de la vida humana. Pone en guardia contra los hechizos y maleficios del diablo, 571 y ss.

26 A. De Madrigal, Supra Genesis Commentaria, cap. 13, sobre el trato de los demonios con seres humanos.

27 P. Binsfeld, Tractatus de confesssionibus maleficorum et sagarum (Colonia, 1586) 371.

28 A. Sucher, Manual de confesores y penitentes, 1570, 71 y ss.

29 "Pruébanlo la experiencia y la razón. La razón nos dice que el hombre no puede obligar al Demonio a cumplir sus promesas. Y la experiencia nos muestra su gran falsía y apetito de engañar. Así, rara vez cumple lo que promete. Y cuando cumple que lo hace algunas veces no es a la fuerza, sino de grado y con segundas, para retener encadenados a los magos, y persuadir a otros, haciéndoles creer que estas boberías pueden tanto", M. Del Río, Disquisitionum, II, q.4 conclusión $2^{\mathrm{a}}$.

M. Del Río, Disquisitionum, II, q. 4. 
primera, que se realiza con cierta solemnidad: el demonio se aparece visiblemente en alguna figura corpórea, y se le rinde lealtad y homenaje ante testigos. La segunda (2) modalidad consistía en formular la solicitud del pacto por escrito, y la tercera (3) a través de un mediador, ya sea el mago o una tercera persona, si el pactante tiene reparos en ver al diablo o conversar con él ${ }^{31}$.

Los elementos del pacto, que se verifican en todas y cada una de sus modalidades, eran los siguientes, según expone nuestro autor: renegar de la fe, retirar la obediencia a Dios y rechazar el patrocinio de la Virgen; renegar del bautismo, por lo que se procede a un remedo de este, que "limpia" del catolicismo. Como consecuencia de ello, se le impone un nombre nuevo. Además, el pactante debe entregar un jirón de su ropa al demonio, pues este -sostiene Del Río- tiene buen cuidado de reclamar una parte de cada cosa: de los bienes espirituales de la gracia, la fe y el bautismo; de los corporales la sangre, como en el culto de Baal al pie del monte Carmelo. Es preciso, además, prestar juramento al diablo sobre un círculo grabado en la tierra, y comprometerse a hacer sacrificios, como matar una criatura estrigándola. Esta noción se encuentra en Bartolomé della Spina, sacerdote dominico, que sigue a Sprenger y $\mathrm{Kramer}^{32}$ en cuanto a la antropofagia y vampirismo de las brujas, especialmente bajo la apariencia de gatas que chupan la sangre a criaturas pequeñas durante el sueño. Y aquí aparece otra de las conductas típicas que configuran jurídicamente el delito de brujería, como ya se advertía antes: el pactante se compromete a asistir regularmente al aquelarre, $\mathrm{y}$ rechazar todos los signos divinos y los actos de piedad, reclutando para el servicio del demonio a cuantas personas pueda ${ }^{33}$. Los pactos tácitos

31 Estas diferencias recuerdan la división entre el pacto implícito, tácito o privado (professio tacita) y el pacto público o solemne (professio expressa) que había sido desarrollada por Grillandus en 1525; es decir, setenta y cinco años antes de la publicación de la obra de Del Río. En el pacto tácito, la bruja prometía lealtad al demonio por medio de otra bruja; el expreso, en cambio, podía firmarse con los ritos debidos en el aquelarre. P. Grillandus, Tractatus de Hereticis et Sortilegiis, I (1536). Cf. P. Binsfeld, Tractatus de confesssionibus... 34, donde se sostiene lo mismo.

32 J. Sprenger y H. Kramer, Malleus maleficarum (circa 1486). Existe versión española, por la que citamos aquí: F. MAZIA (trad.) El martillo de los brujos (Ediciones Orión, Buenos Aires, 1975).

33 Algo parecido se encuentra, años más tarde, en Guazzo, cuando sostiene que son los siguientes pasos: (1) negación de la fe cristiana; (2) nuevo bautizo; (3) eliminación simbólica del crisma bautismal; (4) renuncia a los padrinos y asignación de otros; 
podían ser, a su vez, de dos tipos: (1) cuando alguno a sabiendas se valía de señales supersticiosas aprendidas en los libros o en los discursos de los magos. También era pecado mortal, porque resulta ilícito asociarse concientemente con los malos espíritus, y (2) cuando sin darse cuenta se empleaban signos mágicos, por no saber que son malos e inventados por el demonio.

Del pacto nace una obligación recíproca, pero en realidad el pactante no adquiere derecho alguno, como se indicaba antes; ninguna facultad acompaña a las señales convenidas. Como sostiene Del Río: "son pactos vanos y hueros, porque el demonio jamás guarda la palabra ni se cree obligado por promesa alguna. El que osó mentirle a Cristo, ¿̇a ti te va a respetar?"34. Del pacto se comete -afirma- un gravísimo pecado mortal de idolatría, pues expresamente se da culto de latría a las criaturas. Si la bruja renuncia a su fe, se convierte además en apóstata; pero si no la rechazan del todo, y solo creen que al diablo se le debe este culto, o que el diablo puede lo que la fe católica dice que no puede, entonces son herejes. Empero, si todo es de mentiras, no son apóstatas ni herejes, pero cometen grave pecado mortal, por causa de idolatría. Si lo hicieran por grave temor -sostiene-, obligados por el diablo, cometen pecado mortal menos grave contra la confesión de la fe $\mathrm{fe}^{35}$.

La relación entre magia y demonismo que se observa en Del Río no es nueva; deriva ya de teólogos del siglo IV, quienes sostenían que solo se puede practicar la magia con ayuda del diablo ${ }^{36}$, dando paso para las grandes cacerías. A partir del siglo XIII se configura el discurso teórico necesario para fundar la acción de defensa de la fe, basado en las fuentes

(5) entrega de una prenda de vestir al diablo; (6) juramento de lealtad; (7) escribir su nombre en el libro de la muerte. Cf. F. M. GuAzzo, Compendium maleficarum (Milán, 1608). Existe versión italiana del mismo título que citamos aquí: L. TAMBURINI (trad.), Compendium maleficarum (Einaudi Editore, Turín, 1992) 52 y ss.

M. Del Río, Disquisitionum II, q.4.

M. Del Río, Disquisitionum II, q.4.

Ya se ha mencionado a San Agustín. El Concilio de Elvira (306), Canon 6, rehusó el Viáticum a aquellos que matasen con una encantación (per maleficium) y añade que la razón por tal crimen no podía efectuarse 'sin idolatría'; ya que el culto al demonio es idolatría. Por su parte, el canon XXIV del Concilio de Ancyra (314) imponía cinco años de penitencia a los que consulten magos. Penas similares fueron establecidas por el concilio oriental en Trullo (692). San Gregorio Nacianceno, en un sermón pronuciado probablemente, el 3 de octubre de 379, menciona la leyenda de San Cipriano y el demonio. 
patrísticas de los primeros siglos. Esto se efectuó principalmente a través de (1) la justificación de la existencias de seres puramente espirituales, y (2) su directa intervención en los asuntos del mundo corpóreo. Se les concibe desde entonces como "auxiliares de Dios en la gobernación del mundo" (Concilio de Letrán, 1215) ${ }^{37}$. A fines del siglo XV, se la reconoció (a la brujería) como una forma nueva, organizada y virulenta de herejía ${ }^{38}$. Lo que distingue la brujería en Europa de otras sociedades es, por lo tanto, su componente demoníaco, que se encuentra plenamente desarrollado en la obra de Del Río, una de cuyas bases más probables es la opinión de Eymerich: "todos cuanto invocan al demonio... están sujetos a la jurisdicción del Santo Oficio como herejes, y deben ser castigados como tales"39.

El Malleus Maleficarum, al cual casi con certeza sigue Del Río en estas materias, pone el pacto en el centro del concepto acumulativo de brujería ${ }^{40}$. Sostiene que, para producir algún efecto de magia, el demonio debe cooperar íntimamente con la bruja. El demonio no requiere del

37 Suárez, siguiendo el relato bíblico del ciclo de Tobías, sostiene que los bautizados tienen un ángel y un diablo guardián. El ángel tendría seis funciones en su lucha contra las tentaciones del demonio: alejan los peligros que amenazan el cuerpo y el alma, incitan al bien, reprimen los demonios, presentan las plegarias a ellos, encomendando a Dios, ruegan por su salvación y castigan las faltas cometidas.

38 Cf. B. P. Levack, The Witch Hunt in Early Modern Europe (Logman Grupo, Londres, 1989) Existe versión española, por la que citamos aquí: J. L. GiL (trad.) La caza de brujas en la Europa moderna (Alianza Editorial, Madrid, 1995) 64.

39 N. Eymerich, Directorium Inquisitorium (Barcelona, 1503). Citamos aquí por la siguiente edición: J. MARChENA (trad.) Manual de inquisidores (Imprenta de Feliz Aviñón, Mompeller, 1821) 100: "conoce el Santo Oficio de los que invocan al diablo, los cuales se dividen en tres clases. Los de la primera son los que le tributan culto de latría, sacrificándole, arrodillándosele, cantándole himnos, guardándole castidad, o ayunando en gloria suya, alumbrando sus imágenes o dándoles incienso, etc. Los segundos se ciñen al culto de dulía o hiperdulía, mezclando nombres de diablos con los de los santos en las letanías, y rogándoles que sean sus intercesores con Dios, etc. Los últimos son los que invocan al demonio, dibujando figuras mágicas, poniendo un niño en medio de un círculo, valiéndose de una espada, una cama, un espejo, etc.".

40 El desarrollo completo del concepto de brujería, que se forjará a lo largo de los años de persecución, aparece como tal solo a principios del siglo XV, y se origina en los juicios por herejía y magia que tenían lugar fundamentalmente en los valles de los Alpes occidentales, y que se codificaeon, como se ha mencionado, en un conjunto de tratados que comienzan a ver la luz a partir de 1430. Cf. M. D. BAILey, "From Sorcery to Witchcraft: Clerical Conceptions of Magic in the Later Middle Ages", en Speculum, 76/4 (Oct., 2001) 960. 
auxilio de la bruja para hacer magia; solo de la permisión divina, pero la utiliza porque busca su perdición ${ }^{41}$. Ahora bien, el Malleus Maleficarum considera que hay una parte de la acción de la bruja que no responde a la acción del diablo: "hay algunas cosas en la naturaleza que tienen poderes ocultos, y por eso el hombre no las conoce (como el imán, que atrae el acero)... pero no porque esto sea misterioso debe ser atribuido al poder del demonio" ${ }^{42}$. Esto es perfectamente coherente con la doctrina de la libertad humana, sin la cual, los actos de las brujas no serían imputables, en cuanto se trataría de una mera determinación del acto imperado, de modo semejante a como ocurre con los movimientos de los entes brutos, que son dirigidos hacia su bien por el mandato de la Ley Eterna ${ }^{43}$.

Sprenger y Kramer afirman que los pactos son "reales y auténticos”, que los brujos obran con ayuda del diablo en virtud de un pacto con él establecido $^{45}$; que, a pesar de haber firmado ese pacto, la bruja goza de libertad $^{46}$. Otra diferencia con Del Río se encuentra en que para el $M a$ lleus el pacto debía ser siempre expreso, y además abierto, atendiendo a las condiciones de cada bruja ${ }^{47}$.

Autores contemporáneos se refieren a la lenta configuración del concepto y tipo penal de brujería y sus elementos, formados en virtud de la tradición culta desde el siglo IV hasta el siglo XV como "concepto acu-

\footnotetext{
41 J. Sprenger y H. Kramer, Malleus ... 12.

42 J. Sprenger y H. Kramer, Malleus ... 13.

43 Cf. Santo Tomás de Aquino, Sum. Theol., I-II, q22 a1-2, y I-II, q91 a1.

44 J. Sprenger y H. Kramer, Malleus ... 10.

45 J. Sprenger y H. Kramer, Malleus ... 13.

46 J. Sprenger y H. Kramer, Malleus ... 23.

47 J. Sprenger y H. Kramer, Malleus ... 28 y 70-1. Sobre las "condiciones de cada bruja": "el método con que profesan su sacrilegio mediante un franco pacto de fidelidad a los demonios varía según las distintas prácticas a que son adictas las diferentes brujas. Y para entender esto debe señalarse, ante todo, que existen, como se mostró en la Primera Parte de este Tratado, tres tipos de brujas, a saber: las que dañan pero no pueden curar; las que curan, pero, por algún extraño pacto con el diablo, no pueden dañar; y las que dañan y curan. Y entre quienes dañan, se destaca una clase en especial, que puede ejecutar todo tipo de brujerías y encantamientos, que abarcan todo lo que las otras, cada una por separado, pueden hacer. Por lo tanto, si describimos el método de profesión en su caso, también bastará para todos los otros tipos. Y esta clase está compuesta de aquellas que, contra todos los instintos de la naturaleza humana o animal, tienen la costumbre de comer y devorar a los niños de su propia especie”, J. Sprenger y H. Kramer, Malleus ... 93.
} 
mulativo de brujería"48. En este sentido, la importancia del Malleus Maleficarum fue hacer accesible, por primera vez, al gran público las nociones de dicho concepto acumulativo, ayudado por la bula Summis Desiderantes promulgada por el Papa Inocencio VIII ${ }^{49}$. Era un verdadero manual para inquisidores, similar al Directorium Inquisitorum de Eymerich, de 1376, y tenía la forma de una disputatio escolástica ${ }^{50}$. El Malleus no produjo ni creó, sin embargo, el concepto de brujería; que ya se había configurado cincuenta años antes. Su novedad radica en su carácter sistemático, que ayudó a difundir la cuestión en la mentalidad colectiva. Lo interesante es que la obra de Del Río, en lugar de sustrarse a la influencia de este texto -como ocurrió con algunos de sus compatriotas-, parece por el contrario suscribirla en sus partes esenciales, tal como ocurría con del Valle Alvarado y Becerra y Holguín ${ }^{51}$. Ejemplos de disidencia escéptica los hallamos en las personas de los clérigos Labayen, Oragary y del Doctor Zalba ${ }^{52}$, quienes habían sostenido, a propósito de los casos de brujería en Navarra, que "la materia de brujas era cosa de risa" ${ }^{3}$, y de Andrés Laguna, quien

48 J. Sprenger y H. Kramer, Malleus ... 56 ss.

49 En ella, Inocencio VIII da carta oficial de realidad al fenómeno, y abre las puertas a la ulterior persecución. Sobre el conocimiento de las élites europeas sobre los actos propios del delito de brujería, Cf. A. Rowlands, Witchcarft Narratives in Germany. Rothenburg, 1561-1652 (Manchester University Press, Manchester, 2003) 48 y ss.

50 B. P. LeVACK, The Witch Hunt ... 84.

51 Juan del Valle y Alonso de Becerra fueron los inquisidores que, en enero de 1609, envían las primeras cuatro prisioneras desde Zugarramurdi al Tribunal de Logroño.

52 Visitador del obispado de Pamplona.

53 Valle y Becerra los denunciaron ante el Tribunal de Logroño, afirmando que "comenzaron a levantar disputas y proponer imposibles y perturbar a la gente con diversas opiniones afirmando que no era posible que hubiese brujas, y que todas eran invenciones y levantamientos". Leg. 1679, exp. 2, 10, núm. 28 [b], fols. 1v y 3v. Citado por G. Henningsen, The Witches' Advocate: Basque Witchcraft and the Spanish Inquisition (1609-1619) (University of Nevada Press, Nevada, 1980) 276. $\mathrm{Al}$ respecto, Caro Baroja aporta la siguiente información para interpretar los hechos descritos: "suministra este mismo texto una curiosa información acerco del viaje que había hecho el inquisidor Valle Alvarado visitando Lesaca, Vera y otras villas de la montaña, pasando luego a San Sebastián y Tolosa, donde halló al obispo de Pamplona, de visita diocesana también; al hacerse ciertas prisiones, el obispo escribió al inquisidor en favor de María de Endara, viuda, residente en Echalar, accediéndose a que la prisión no se hiciera en la forma común y para que compareciese en Logroño con don Miguel de Oragaray, presbítero. Allí se dice también que Labayen, el visitador del obispado de Pamplona Doctor Zalba y otros empezaron a negar la existencia de brujas, incluso ante el prelado. De su actitud habían dado cuenta los comisarios, como va expuesto. Labayen, además, vestido de peregrino, emprendió un viaje, ca- 
afirma que "podemos conjeturar que todo cuanto dizen y hazen las desventuradas bruxas es sueño" 54 .

\subsection{El maleficio}

Una vez que la bruja había realizado su primera y nuclear fechoría, consistente en aliarse con poderes demoníacos, podía proceder a la segunda conducta típica que configuraba el delito de herejía en la especie de la brujería: la realización de maleficios. Dice Del Río: "las obras de los magos las ejecuta el demonio a través del pacto" ${ }^{5}$. Y las obras de la bruja son básicamente las que siguen: adivinación, maleficio, vuelo nocturno y participación en el aquelarre. El Papa Juan XXII, en la bula Super Illius Specula, de 1326, había asimilado el maleficio a la magia diabólica ${ }^{56}$.

El maleficio es la primera conducta típica propiamente tal de la bruja, en el concepto acumulativo - después del pacto-, consistía en la realización de actos dañinos (maleficia) por medio de algún tipo de poder sobrenatural ${ }^{57}$. Los autores de estos delitos eran denominados malefici o maleficae. Los maleficia eran siempre dañosos, realizados por venganza

mino de Santiago en penitencia; pero, en realidad, lo que hizo fue ir a Logroño y pretender sonsacar al alguacil mayor del Santo Oficio, Juan de Jaca, y saber si él estaba entre los posibles acusados: quiso también hablar con María de Endara. El alguacil dio cuenta al Tribunal, de sus actuaciones y este, de modo indirecto, recomendó a Labayen que si se sentía culpado de Brujería, lo confesase también. Al fin, Labayen llegó a hablar con el inquisidor Becerra, para hacer la defensa de la mujer y de otros inculpados, conforme a las experiencias que él y otros habían efectuado, llevando a las mujeres a sus casas, velándolas y preguntando luego a los chicos si les habían llevado, a lo que estos respondieron que sí. Le atajó el Inquisidor, reprendiéndole y tomando la cosa por el lado de la pudibundez: por lo mal que parecía que él y sus compañeros llevaron a sus casas a mujeres. Labayen, dice la carta, lloró al oír esto. Desapareció luego y volvió o aparecer, de regreso de Santiago, según declaró. Se acusa luego también a Labayen de que era padre de la criatura que había dado a luz María de Endora... y se dan otros detalles acusatorios. Mentira o verdad. Para el caso es lo mismo. Que Labayen se interesaba por María, es evidente: pero el problema era otro. El problema que molestaba a los inquisidores era el de que se experimentara negativamente y que el Doctor Zalba, delante del obispo mismo, pusiera en disputa la cuestión de la Brujería", J. CARO BARBoja, "De nuevo sobre la historia de la brujería (1609-1619)”, en Príncipe de Viana 56/206 (1995) 17.

54 A. Laguna, Comentarios a DIOSCORIDES, Pedacio, Acerca de la materia medica y de los remedios mortíferos (Salamanca, 1570) 422.

55 M. Del Río, Disquisitionum, q. 7.

56 R. García Carcel, “¿Brujería o brujerías?”, en Historia, 16/136 (1987) 44-50.

57 H. Robbins, Enciclopedia... 379. 
o maldad, y podían revestir dos formas: el damnum minatum (amenaza de obrar mal), o malum secutum (el mal efectivamente producido). Todo tipo de desgracias y calamidades, para los que no se encontraba una explicación inmediata, caían bajo esta rúbrica. Ciento sesenta años antes que Del Río, Nidier afirmaba que la bruja podía obrar maleficios y daños a hombres y objetos de siete maneras diferentes: (a) inspirando amor; (b) inspirando odio; (c) produciendo impotencia; (d) provocando enfermedades; (e) despojando de la vida; (f) privando de la razón, y (g) dañando objetos y animales ${ }^{58}$.

Los métodos más frecuentes para obrar maleficios eran las drogas tóxicas y los muñecos de cera. El maleficium, sin embargo, no era un hechizo, pues este último designaba la práctica de la magia mediante algún tipo de procedimiento mecánico o manipulatorio; es decir, se trataba de una habilidad adquirida. Sus diferencias con el maleficio residían en que (1) el hechizo podía ser bueno -según parte de la doctrina, que no incluye a Del Río como ya se ha visto-, y por lo tanto se trataba de un concepto más amplio, y (2), además, algunos actos maléficos no suponían el uso de una técnica, como el mal de ojo o desear la muerte de alguien.

El maleficio puede entenderse en sentido estricto y en sentido amplio. En el primer caso, indica el daño producido a otro por artes demoníacas. Esto ya está en el Malleus Maleficarum, cuando sostiene que "pues en verdad, este es el fin de toda brujería; se trate de efectuar encantamientos por medio de la mirada o por una fórmula de palabras, o por cualquier otro hechizo ${ }^{59}$. En sentido amplio, se refiere a todas las actividades mágicas de la bruja, que los teólogos e inquisidores se entretienen en describir. Ninguna de estas dimensiones, dice Martín del Río,

58 J. Nider, Formicarius, V, Basilea, circa 1435. La importancia de este texto radica en la especificidad de sus fuentes sobre casos "reales" de brujería. Cf. A. Kors y E. Peters, Witchcraft in Europe (1100-1700): a Documentary History (University of Pennsylvania Press, Philadelphia, 2001) 155.

59 J. Sprenger y H. Kramer, Malleus ... 14. También p. 42: "Pero contra esto. Es imposible producir un efecto sin su causa; y las acciones de las brujas son tales, que no pueden llevarse a cabo sin la ayuda de los demonios, como se muestra por la descripción de ellas en San Isidoro, Etica, VIII. Las brujas son llamadas así por la enormidad de sus hechizos mágicos; pues perturban los elementos y confunden la mente de los hombres, y sin ninguna pócima venenosa, sino que nada más en virtud de encantamientos, destruyen almas, etc. Pero este tipo de efectos no pueden ser provocados por la influencia de los astros mediante la, acción de un hombre". 
siguiendo a Santo Tomás, puede mudar realmente el orden natural ${ }^{60}$. Las acciones más significativas del maleficio, de acuerdo con Del Río, eran las siguientes:

\section{a. Poder sobre la propiedad, fortuna o bienes exteriores (q. 12)}

Dentro de esta categoría, afirma el canónigo Del Río, el demonio puede, a través de la bruja, hacer morir rebaños esparciendo veneno, frotándolo o aplicándolo de cualquier otro modo. Otras veces por movimiento local, si se introduce en su cuerpo y los ahoga, despeña o despedaza. También pueden arrebatar mieses y frutos ajenos, trasladándolos a otro lugar, como decía San Agustín ${ }^{61}$. Podía también estropear todo tipo de frutos de la tierra, o provocar esterilidad en los campos. Se suponía que las brujas recibían del demonio - para estos efectos- un polvo fino, que se esparcía sobre la tierra.

Además, ya en el ámbito de los bienes incorporales, la opinión tradicional sostenía que la bruja estaba en condiciones de perjudicar la fama de terceros por variados medios, desde la ilusión de los sentidos hasta presentarse ante ellos como figuras de personas inofensivas. Del Río, en un arranque de sensatez dentro de su concepción general del maleficio, acota: "por mi parte, hasta ahora no he leído ni oído que Dios haya permitido tal cosa en relación con el crimen de magia”. También era posible -se argumentaba- dañar la fama de un tercero depositando en determinados lugares instrumentos de maleficio, donde pareciera que los habían escondido los inocentes a los que se buscaba difamar, y se les tuviera por maléficos ${ }^{62}$.

Dentro de los actos del maleficio, y de un modo general, se incluían, además de los actos contra la propiedad de bienes corporales e incorporales, todas aquellas actuaciones de la bruja distintas del vuelo nocturno y del aquelarre. La Bula Summis Desiderantis - de la que nuestro autor toma base- indica que "ha llegado a nuestros oídos que gran número de personas de ambos sexos no evitan el fornicar con demonios súcubos e íncubos, y que mediante sus brujerías, hechizos, conjuros, sofocan, extinguen y hacen perecer la fecundidad de las mujeres (el efecto dañoso),

60 M. Del Río, Disquisitionum, q. 10. Santo Tomás, Suma contra Gentiles, 3, 108.

61 San Agustín, La Ciudad de Dios, 1, 8.

62 Esto también se hacía en sentido inverso, en relación con las acusaciones de brujería. 
y la propagación de los animales, la mies de la tierra, las uvas del viñedo y el fruto de los árboles, así como a los hombres y mujeres, y al ganado y otras clases de animales, las vides y los manzanos, los pastos y el maiz y otros frutos de la tierra: haciendo y procurando que los hombres y las mujeres, el ganado y otros animales sufran y sean atormentados tanto desde dentro como desde fuera, de modo que los hombres no pueden engendran y las mujeres concebir: e impiden la acción conyugal de los hombres y las mujeres". En la tradición española, encontramos la afirmación de que, si la bruja deseaba vengarse de alguno, acudía al demonio. La venganza debía ser consumada personalmente por la bruja, auxiliada por Satanás, que dormía a las víctimas, dándole ocasión a la bruja de realizar el maleficio ${ }^{63}$.

Como puede verse, tanto la bula de inocencio VIII como el Malleus Maleficarum marcan la pauta de lo que debe ser entendido por actos de maleficio, o actos dañosos realizados por la bruja en concomitancia con el demonio. La obra de Del Río no se aparta especialmente en este punto de esta tradición, que conforma la idea acumulativa del delito de brujería; pero muestra, como hemos visto, escepticismo respecto de ciertos medios extraordinarios, como la ilusión de los sentidos, y la presentación corpórea ante otros con aspecto de terceros. Conocido era el debate sobre la corporización de los seres angélicos, y la dificultad para llegar a explicarlo, una vez establecida la concepción de que las substancias espirituales no se encontraban naturalmente unidas a un cuerpo ${ }^{64}$.

63 Sentencia conjunta del Tribunal de Logroño, folios 392v-393r. Citado por G. Henningsen, The Witches Advocate... 134.

64 He aquí la opinión de Santo Tomás, frente al argumento de Orígenes de que solo la naturaleza de Dios, esto es, la del Padre, la del Hijo y la del Espíritu Santo, tienen la propiedad de existir sin sustancia material y sin estar unidas a nada corpóreo: "Los ángeles no tienen cuerpo al que estén unidos por naturaleza. Pues lo que en una naturaleza es accidental, no se encuentra en ella universalmente. Ejemplo: Puesto que tener alas no es de la esencia del animal, no todos los animales las tienen. Ahora bien, puesto que entender no es un acto del cuerpo ni de ninguna facultad corpórea... tener un cuerpo unido no pertenece a la esencia de la sustancia intelectual en cuanto tal, sino que se trata de un accidente que se añade a una determinada sustancia intelectual por otros motivos. Esto es lo que le sucede, por ejemplo, al alma humana, a la cual le corresponde la unión con el cuerpo por ser imperfecta y por estar en potencia dentro del género de las sustancias intelectuales, ya que no tiene en su naturaleza la plenitud de la ciencia, sino que la adquiere por medio de los sentidos corporales tomándola de las cosas sensibles. Pero siempre que en un género hay algo imperfecto, es necesario que en el mismo género preexista algo 


\section{b. Las asambleas nocturnas (q. 16)}

Este es un punto central del tratado, por cuanto la concepción del Aquelarre o Sabbat permitía, en coherencia con el concepto acumulativo de bujería ya mencionado, confirmar que esta no consistía solo en un conjunto de delitos aislados y totalmente inconexos, sino más bien en una conspiración masiva, de origen demoníaco ${ }^{65}$.

La integración del aquelarre en el concepto acumulativo fue, como todas estas conductas, paulatina, y pasó por diversas etapas. En el manual de Bernardo Gui por ejemplo (1324) -texto muy utilizado en los siglos XIV y XV-, el aquelarre o sabbat ni siquiera aparece ${ }^{66}$. En la obra de De Lancre ${ }^{67}$, sin embargo, el tema es profusamente descrito, realizando detalladas descripciones de lo que en este supuestamente ocurría. Pero no es el primero en describirlo. Bodino, por ejemplo, redacta un extenso pasaje sobre la música y la danza del aquelarre ${ }^{68}$, Rémy, por su parte, describe los violines y gaitas que se escuchan en el sabbat, y cómo los demonios bailan espalda con espalda en una danza salvaje que pierde a las mujeres ${ }^{69}$.

El tratamiento que hace Del Río no es original, y se apega frecuentemente a los textos clásicos, lo que muestra que, a la altura en que nues-

perfecto. Por lo tanto, en la naturaleza intelectual hay algunas sustancias intelectuales perfectas que no precisan adquirir su ciencia tomándola de las cosas sensibles. Así, pues, no todas las sustancias intelectuales están unidas a los cuerpos, sino que algunas están separadas de ellos. A estas las llamamos ángeles”. Cf. SANTO TOMÁs, Sum. Theol., I, q.51, a.1.

65 Algunos consideran que la palabra "aquelarre" no es vasca, sino de una construcción culta que proviene del lenguaje jurídico. Esto ha sido corroborado por Henningsen, quien la atribuye el carácter de una voz erudita de principios del siglo XVII; concretamente, del día 14 del mes de febrero de 1609, fecha en que el Tribunal de Logroño recibe un nuevo grupo de presos de Zugarramurdi, y el 22 de mayo del mismo año, en que la palabra aparece por primera vez. Es muy posible que su creador fuera el inquisidor Juan del Valle, ya mencionado. Cf. G. Henningsen, "El invento de la palabra aquelarre", en J. M. UsanÁrIZ GaraYOA, Historia y humanismo. Estudios en honor de Valentín Vázquez de Prada, vol. I (Eunsa, Pamplona, 2000) 351-9.

66 B. Guidonis, Practica Inquisitionis Heretice Pravitatis. Hemos tenido a la vista la edición de Alphonse Pivard (París, 1886)

67 P. De Lancre, Tableau de l'inconstance et instabilité de toutes choses (París, 1607)

J. Bodin, De la démonomanie des sorciers (París, 1580) 88.

69 N. Rémy, Demonolatriae libre tres, 1595. Hemos tenido a la vista la versión inglesa, M. R. Summers (trad.) Demonolatry (Kessinger Pub., Londres, 2003) 63. 
tro autor escribe, la asamblea nocturna era considerada habitualmente como incorporada al delito de brujería. La fusión de las ideas del pacto y el aquelarre en el concepto acumulativo de brujería no se produjo, sin embargo, sino hasta el siglo XV; antes, no estaban asociadas. El Malleus Maleficarum se refiere en reiteradas ocasiones al pacto pero no habla casi de la adoración colectiva. Como dice $\operatorname{Roper}^{70}$, todas estas historias formaban parte de la tradición demonológica, y pueden encontrarse en Bodino, Guazzo, Boguet ${ }^{71}$ y el propio Del Río, para quienes, en el momento en que escribían, tales narraciones constituían referencias clásicas del conocimiento universalmente aceptado sobre el tema ${ }^{72}$.

El aquelarre o "convento", como lo llama Del Río, era un supuesto culto colectivo, donde se practicaban ritos blasfemos e inmorales. Esta conducta era considerada gravísima, por su extrema nocividad social; de hecho, es muy probable que, sin la creencia en el aquelarre, la caza de brujas habría sido una operación judicial de mucho menor envergadura ${ }^{73}$.

Todas las sociedades producen mitos sobre personas que subvierten el orden y corrompen la comunidad; ello parece ser psicológicamente necesario para identificar las normas y autoafirmarse. La creencia en el aquelarre (baile desnudo, infanticidio caníbal) es la versión europea de una pesadilla común a muchas culturas anteriores. Posee, sin embargo, características distintivas que reflejan la influencia del cristianismo en la concepción de la asamblea. Los romanos se habían hecho la imagen, durante los primeros tiempos, de que los cristianos eran miembros de una organización secreta que practicaba el infanticidio, el canibalismo (tergiversando la concepción de la Eucaristía) y el incesto. Otra fuente del aquelarre fue la idea de que los herejes (magos y judíos) eran idólatras. Y aun otra: las reuniones en secreto de los herejes. De acuerdo con todo esto, los teólogos de los siglos XII y XIII elaboraron un estereotipo de hereje como adorador secreto del diablo, nocturno y sexualmente promiscuo, que sirvió de base a la configuración del delito de asamblea nocturna.

70 L. Roper, "Witchcraft and the Western Imagination", en Transactions of the Royal Historical Society, Sixth Series, 16 (2006) 128 (117-141).

71 Boguet, Henry, Discourse des sorcieres, Lyon, 1603.

72 L. Roper, "Witchcraft and the Western Imagination"... 126.

73 Cf. B. P. Levack, The Witch ... 66 ss. 
Existía la convicción entre los teólogos y demonólogos de que a Satanás le correspondía también una liturgia inversa a la cristiana, con sus oraciones, sacerdotes, sacramentos y ofrendas ${ }^{74}$. Por esto, la asamblea nocturna es descrita como una reunión profana e inversa a la misa: como un espejo puesto al revés: cada uno de los elementos sagrados tiene su corresponiente en el sabbat. Era una mímesis de la liturgia cristiana, que se remontaba a cultos paganos antiguos. Algunos de los elementos descritos en el sabbat por los autores son los siguientes: a) La reverencia al demonio, a través del llamado "beso negro", parodia del beso en la mano y el respeto al sacerdote ${ }^{75}$; b) la rareza de los materiales y las palabras usadas (ungüentos, polvos, etc.), a diferencia de la misa, que incluía pan, agua, vino y aceite, c) Las unciones corporales, a imitación de los sacramentos $^{76}$; d) la oposición al voto solemne a Dios que se expresa en el bautismo, a través del voto en manos del demonio, que consistía en renegar de la fe, pisar la cruz y las reliquias ${ }^{77}$; e) el sacrificio de niños, que remedaba el sacrificio de la Eucaristía ${ }^{78}$; f) la vinculación con la mística, a través de la marca con que el demonio señalaba a los asistentes, y que es una versión herética de los estigmas ${ }^{79}$.

A propósito de esto último, Del Río se pregunta si la asamblea nocturna no es acaso una ilusión diabólica, aprovechando la conexión con la mística, como afirma Juan de Salisbury ${ }^{80}$, una especie de histeria colectiva. Su conclusión discurre más bien por el argumento de la certeza de la evidencia, inclinándose por la existencia efectiva del sabbat. "se trata del consenso unánime de todas las épocas y todos los pueblos, de personas de ambos sexos, incluido el clero y la nobleza, más las confesiones de los reos. Contra todo eso no hay presunción que valga" ${ }^{81}$. El mismo aporta testimonios de la presunta acción para asistir al sabbat "las brujas ocasionalmente mencionan cómo el diablo abre una grieta en las paredes, por

74 M. TAusiet, "La imagen del sabbat en la España de los siglos XVI y XVII a través de los tratados de brujería y superstición”, en Historia Social 17 (1993) 6 (3-20).

Castañega, Tratado de Supersticiones y Hechicerias, cap VIII 51.

76 Castañega, Tratado de Supersticiones..., cap. III 26.

77 G. Navarro, Disputa XX, folios 52-4.

78 Castañega, Tratado de Supersticiones..., cap. IX 53.

79 A. De Torquemada, Jardín de las flores curiosas (Castalia, Madrid, 1982) 310.

80 Policrático, 2, 17.

81 M. Del Río, Disquisitionum, q. 16, p. 331. 
donde puede ellas salir y entrar, haciendo luego que se junten y suelden las partes" $"$.

Ahora bien, para la asistencia al aquelarre, el modo tradicional era la figura del vuelo nocturno, procedimiento por el cual la bruja presuntamente se trasladaba hasta el lugar de la asamblea. Es un corolario de la creencia en dichas reuniones: de este modo, podían congregarse en zonas remotas, sin que se descubriera su ausencia a la mañana siguiente. Esta creencia tenía orígenes mucho más populares que los anteriores: (1) se pensaba que las mujeres podían transformarse de noche en lechuzas o strigae, que solían devorar niños. Las strigae, término que pasó a ser una de las muchas palabras latinas para designar a las brujas, se llamaban también lamiae, en referencia a la mítica reina de Libia, amada de Zeus, que sorbía la sangre de los niños en venganza porque Hera había asesinado a los suyos, y (2) se creía que las mujeres salían de noche en una cabalgata con Diana, la diosa romana de la fertilidad, identificada a menudo con Hécate, la diosa del mundo subterráneo y la magia. En Alemania se la identificaba con Holda o Perchta, diosa tanto aterradora como nutricia (al igual que Diana). La Iglesia consideraba que las diosas de la fertilidad eran en realidad demonios. La asociación entre una y otra figura estaba, pues, conformada, y solo necesitaba un pequeño empujón formal, que corrió de la mano de los manuales para los inquisidores ${ }^{83}$.

El Malleus consideraba que si bien eran sueños, no se podía negar que el diablo tenía el poder de transportarlas realmente. Así pues, en el siglo $\mathrm{XIV}$, coexistían tanto la idea de que era imaginación como la de que podía ser realidad. A veces se las describía cabalgando animales, a la manera de las seguidoras de Diana. Otras veces montaban palos que podían estar ahorquillados como una vara de zahorí. La escoba y la rueca eran símbolos de la bruja. Además la escoba era símbolo fálico. Si volaban sin nada, era debido a los ungüentos. El excremento de sapo, utilizado por las brujas vascas como espíritus auxiliares, tiene alucinógenos. Es posible, pues, que lo imaginaran. Pero también otros ungüentos eran inofensivos, como la sangre de murciélago y el hollín, y todos los relatos primitivos sobre su uso indican que la untura se aplicaba al palo de escoba, no a la bruja. Andrés Laguna, por su parte, comenta haber encontrado un ungüento de color verde en la choza de dos supuestas brujas.

\footnotetext{
M. Del Río, Disquisitionum, q. 21, p. 357.
}

83 Cf. B. P. Levack, The Witch ... 74 ss. 
Habiendo untado con él el cuerpo de una mujer que no podía dormir, esta habría caído en un profundo sueño, durante el cual tuvo todo tipo de visiones extraordinarias. Tal como Laguna escribiera posteriormente en las anotaciones a su traducción de la Materia Medica de Dioscórides -ya citado-, esta experiencia le llevó a concluir que las brujas en realidad no se mueven, y que solo vuelan y asisten a sus asambleas en sueños ${ }^{84}$.

Del Río, sin embargo, se inclina por la opción contraria a la mera ilusión (lo cual era, por lo demás, la opinión más extendida entre los teólogos de España, Italia y los católicos de Alemania): "así, la segunda opinión, que juzgo verdadera, dice: a veces el demonio traslada de verdad a las brujas de un lugar a otro, cabalgando a lomos de un macho cabrío u otro animal -generalmente fantástico-, o en alguna caña verdadera, o un mango de escoba también verdadero, pero manejado y sostenido por el demonio, para que asistan físicamente a la asamblea infame" ${ }^{\prime 5}$. El "animal fantástico" era el propio demonio, que asumía forma y cuerpo aéreo. Cito el testimonio de Juan Bautista Porta: "aunque ellas combinan mucha superstición, el efecto puede ser natural si bien se mira. Diré lo que las mismas me contaron. En un recipiente de cobre en que han puesto a cocer grasa de niños, separan el sobrenadante, concentrando el del último hervor. Este lo reservan para usarlo luego... así parece que viajan por los aires, y no en noches de novilunio; celebran banquetes con música y danza, y lo que más apetecen, acostarse con jóvenes..." ${ }^{86}$.

Como dice Caro Baroja, Del Río ofrece un versión del sabbat tomando elementos "de aquí y de allá", y citando a Rémy ${ }^{87}$ y a Binsfield: una vez en la asamblea, que comienza a medianoche, dice Del Río, "se enciende por lo general una gran hoguera”. El demonio preside, sentado en un trono, en forma horrible, casi siempre de macho cabrío o de perro. Y se le acercan para adorarle, mas no siempre del mismo modo Asegura que se remeda el bautismo y el sacrificio de la misa, mediante procedimientos que parece mejor no detallar. En este punto, si los había, se realizaban los sacrificios. Después, se sientan a las mesas en un convite con manjares que proporciona el diablo, o que ha llevado cada

\footnotetext{
84 G. Henningsen, "The Witches' Flying and the Spanish Inquisitors, or How to Explain (Away) the Impossible", en Folklore, n. 120 (2009), p. 59 (57-74).

86 Magia natural, c. 26, pp. 121-2.

87 N. Rémy, Demonolatriae libre tres, 1595.
} 
cual. Toman asiento por orden de dignidad o hacienda, cada cual con su respectivo demonio familiar. Cuentan sus fechorías y comen, probablemente encapuchados. Y después del banquete, cada demonio de la guarda toma de la mano a su discípula, dándose la espalda, hacen corro todos asidos de las manos y, sacudiendo la cabeza como locos, ejecutan alguna contradanza ${ }^{88}$.

\section{CONSIDERACIONES FINALES}

Sorprende la enorme imaginación, apoyada por la tradición mitológica, que los inquisidores europeos aplicaron a la cuestión de la brujería y a las conductas que constituían delito, agrupadas, como hemos visto, en tres grandes focos: el pacto con el demonio, por el cual la bruja pasa a situarse en el plano de la herejía, y el maleficio o acción dañosa sobre los terceros, que extrae su fuerza del pacto; el vuelo nocturno, que en ocasiones es reemplazado por otras vías mágicas que ofrece el demonio, y la asamblea nocturna, que repugnaba a la conciencia por sus acciones impuras, y permitía conectar a la bruja solitaria y aislada con toda una legión de adoradores del demonio.

¿Cuál es el papel que desempeña Martín del Río, y concretamente el Libro II de las Disquisitionum Magicarum en este contexto? Sabemos que la obra fue muy famosa durante el siglo XVII; incluso algunos han llegado a afirmar que el texto de Del Río fue el natural sucesor del $\mathrm{Ma}$ lleus como principal referencia para jueces e inquisidores ${ }^{89}$; de hecho, pueden contarse al menos veinticuatro ediciones publicadas desde la primera edición, hasta la de Venecia, en 1747. El texto no contiene, sin embargo, elementos originales para aportar a la tradición, en especial si se compara la obra con la manualística francesa destinada a los inquisidores. Su interés reside más bien en su valor relativo al momento en que se escribe, y en que ve la luz.

Martín del Río, como se ha insinuado antes, se aparta un tanto de la posición adoptada por un segmento significativo de la Inquisición española, en cuanto sanciona las teorías y procedimientos aconsejados en el Malleus Maleficarum, y creía firmemente en los actos típicos del delito

88 M. Del Río, Disquisitionum, q. 16, p. 339.

89 C. H. Lea, citado por J. P. Davidson, recensión a Martín Del Río, Investigations into Magic (Maxwell-Stuart P. G., trad.), en The Sixteenth Century Journal, 33/1 (Spring, 2002) 277-278. 
de brujería, uniéndose así a la tradición europea del concepto acumulativo de brujería y la conspiración diabólica mundial. La orientación doctrinal peninsular de los siglos XVI y XVII, por el contrario, muestra más bien un creciente escepticismo por la brujería, salvo episodios aislados como el de Zugarramurdi ${ }^{90}$. No hay que olvidar que la Inquisición española fue una de las primeras, en toda Europa, en abolir la pena de muerte como castigo al delito de brujería ${ }^{91}$. Los inquisidores Fernando de Valdés ${ }^{92}$, por ejemplo, y Salazar Frías ${ }^{93}$, hacen gala un fino sentido común en sus opiniones. Caro Baroja, por su parte, justifica esta tendencia

90 Aun en este caso, el Consejo de la Inquisición, frente a la credulidad de las autoridades locales, remitieron un cuestionario a los inquisidores de Logroño, manifestando sus reservas. La situación era la siguiente: en el otoño de 1608 volvió a Zugarramurdi una muchacha llamada María, de veinte años, que había emigrado a la ciudad de Ciboure, donde tuvo ocasión de presenciar la caza de brujas llevada a cabo por Pierre de Lancre. María, para llamar la atención, empezó a contar las cosas que había visto, y cómo utilizaban las cuevas de Zugarramurdi para realizar aquelarres; ofreciendo nombres de supuestos asistentes. Fruto de estas intrigas, en enero de 1609 llegó a la localidad un comisario de la Inquisición, iniciando un procedimiento que culminaría con el Auto de Fe celebrado en Logroño en noviembre de 1610, con siete brujas quemadas en persona y cinco en efigie. Cf. A. Morgado García, Demonios, magos y brujas en la España moderna (Servicio de Publicaciones de la Universidad de Cádiz, Cádiz, 1999) 129, y F. IDOATe, Un documento de la Inquisición sobre brujería en Navarra (Aranzadi, Pamplona, 1972) 39 y ss. Cf. también D. Gifford, "Witchcraft and the Problem of Evil in a Basque Village", en Folklore, 90/1 (1979) 11-17.

91 A mediados del siglo XVI, las autoridades vascongadas de la Inquisición solicitaron a sus correspondientes de Navarra no ceder ante las peticiones populares de quema de brujas. En 1540 Pedro Pacheco, Obispo de Pamplona, envía una circular a todos los sacerdotes de su Diócesis advirtiendo que la brujería era una falacia, recomendando someter a las acusadas de brujería a un examen médico, y explicando que la psicosis se debía a la ignorancia, por lo que era necesario que se enviaran predicadores a las zonas más necesitadas. Cf. Morgado, Demonios, magos... 124.

92 Preguntado Valdés en un proceso de 1525 sobre la realidad misma de las brujas, se contesta que sin dudar que algunas personas ejercieran tal profesión. Luego era necesario aclarar si después de los ungüentos eran realmente transportadas por el demonio, o los fenómenos del aquelarre pasaban solo en su fantasía, optando Valdés por lo segundo. Cf. J. L. GonZÁlez Novalin, El Inquisidor General Fernando de Valdés (1483-1568). Su vida y su obra (Universidad de Oviedo, Oviedo, 1968) 64.

93 Hennignsen llama a Alonso de Salazar Frías "el abogado de las brujas", justamente por afirmar que las supuestas conductas sobrenaturales eran producto de la imaginación. Cf., G. Henningsen, The Witches' Advocate..., p. 60. Salazar fue uno de los tres juristas que integraron el Tribunal de Logroño en el asunto Zugarramurdi; y de no haber sido por él, las víctimas habrían sido muchas más. A propósito de este 
afirmando que la falta de beligerancia del Santo Oficio sobre la brujería se debería esencialmente a la formación jurídica de la mayoría de los inquisidores españoles, mucho más instruidos en la jurisprudencia que en asuntos humanistas y teológicos, con una marcada actitud escéptica ante las manifestaciones de brujería ${ }^{94}$. Henningsen sostiene que en España existía una tradición de escepticismo hacia la creencia en la brujería, que se remonta al teólogo Fray Lope de Barrientos, que murió siendo arzobispo de Cuenca en 1469, rechazando todo tipo de maleficios y vuelos nocturnos ${ }^{95}$.

Para comprender esta tensión, es preciso separar la imaginería popular y las afiebradas descripciones de los manuales, de los fundamentos teológicos propuestos para dar razón de ellos. Los desarrollos de Santo Tomás y San Agustín, de Vitoria y de Suárez no se apartan un ápice de la ortodoxia teórica y teológica sobre las criaturas espirituales y su acción sobre el mundo, afirmando la existencia de la acción del demonio en el mundo. Es decir: desde el punto de vista teológico, no existía objeción para concebir la existencia de fuerzas suprahumanas actuando sobre el mundo; más bien, ello se inscribía dentro de la estructura lógica de la creación. Asunto distinto es la cuestión teológica de cómo ocurriría la corporización de los ángeles, y si los demonios pueden o no realizar artes mágicas a través de los seres humanos, cuyo desarrollo nos apartaría significativamente del objeto de este trabajo ${ }^{96}$. Ahora, bien, esta acción demoníaca sobre el mundo se hacía más difícil de probar cuando se trataba de atribuir a personas concretas la posibilidad de ejecutar actos extraordinarios, con conjurar y volar al aquelarre.

Desde el punto de vista jurídico, el llamado concepto acumulativo de brujería establece a partir del siglo XIV los elementos básicos del delito de brujería, que no son peculiares en Martín del Río, salvo por contener todas las figuras típicas, ya bordeando el siglo XVII. Del Río se encuentra a cierta distancia de la virulencia de Spranger y Kramer, pero algo menos de los encendidos discursos de Pierre de Lancre. Su enfoque, a pesar de ser proclive a sostener la realidad de los actos ilícitos

juicio, escribió en 1613, Salazar escribe: "no hubo brujas ni embrujados hasta que se habló y se escribió de ello".

94 J. Caro BAROja, El señor inquisidor y otras vidas por oficio (Alianza, Madrid, 1970)

51 y ss.

95 G. Henningsen, “The Witches' Flying...”, p. 58.

96 Cf. Santo Tomás de Aquino, Sum. Theol., I-I, q.51 ss. 
de la bruja, es más reposado y de fuente escolástica, conservando de ese modo un cierto tono académico que aleja a las Disquisitionum Magicorum de presentarse como un documento destinado exclusivamente a instruir a los inquisidores, como sería el caso de Eymerich o Guazzo, y menos todavía como un panfleto dirigido a las poblaciones iletradas, como ocurría frecuentemente en Alemania e Inglaterra. Esta tonalidad mesurada, doctrinal y fuertemente jurídica, parece darle la razón a la interpretación de la actividad inquisidora española como un factor de equilibrio en el contexto general de la caza de brujas europea, y justifica también, en parte, su influencia y sus múltiples reediciones. En mi opinión Del Río, a pesar de su objetivo pronunciamiento a favor de la bruja como realidad exterior, objetiva y consensual, no rompe completamente la mesurada tradición española de que habla Caro Baroja, sino que de algún modo la reafirma, en virtud de la cautela doctrinal con que aborda una cuestión que, a pesar de todo, sigue considerando como real.

El Disquisitionum magicarum libri VI es un manual completo y docto, pero al mismo tiempo extenso y un tanto confuso. En sus seis libros se recogen documentos antiguos y modernos, junto con textos curiosos e insólitos sobre las supersticiones, los demonios, los maleficios, la adivinación, los remedios lícitos e ilícitos, los procesos, etc.; las opiniones a favor y en contra de la brujería, los conventículos, los viajes diabólicos, etc. Alaba a aquellos tratadistas que con su doctrina han ayudado a alimentar la «caza de brujas». Entre ellos destaca a Nider y a Sprenger de cuyos textos se sirve tanto por sus aspectos más teóricos como por los ejemplos prácticos que incluyen, "quia docti theologi fuere, et in his, de quibus agimus, rebus exercitatissimi, et quaecumque tradidere, his similia nostra videt aetas, et recentiores ea confirmant omnia» (liber III, pars I, quaestio 4, sectio 5). Entre los franceses admira a Rémy, y de los italianos estima a Grillando y a Spina.

Una de las primeras críticas que ha recibido la obra de Del Río procede de un español contemporáneo suyo, el padre dominico Tomás Maluenda, quien declara que el Disquisitionum magicarum libri VI debería estar prohibido porque con el pretexto de combatir la magia, la enseña. Pese a ello, Del Río es leído y admirado durante el siglo XVII. En España tiene como seguidor a Francisco Torreblanca Villalpando, jurista cordobés, que escribe dos libros acerca de la magia desde un punto de vista estrictamente legal. El primero, Epitomes delictorum, incluso es utilizado 
por los historiadores de la Inquisición al tratar de cuestiones de procedimiento ${ }^{97}$. También en Portugal se percibe la influencia de la doctrina de Del Río en un libro de Emanuel do Valle de Moura sobre los encantos y ensalmos, De incantationibus seu ensalmis ${ }^{98}$.

Admirado u odiado, lo cierto es que Martín del Río marca un antes y un después en el tema de la brujería. Su raíz humanista se evidencia en el caudal de conocimientos que sobre la magia discurre por su cabeza; ideas estas que provocan una lucha interna entre la creencia y la razón de un hombre, a medio camino entre el pensamiento renacentista y el barroco. Su propia mente es un compendio de controversias que solo encuentra coherencia en el filo de entre siglos. A partir del Disquisitionum magicarum libri VI los filósofos y teólogos comienzan a plantearse, desde un plano verosímil, el mundo concerniente al demonio con todas sus manifestaciones conocidas, pues produce extrañeza el hecho de que una persona como Del Río pueda creer en supersticiones vanas. Nace una necesidad de enfocar e interpretar la realidad a partir de una base más racional y lógica; e involuntariamente el impulso hacia el cambio en este sentido es generado por el mismo Martín del Río. 
